\title{
Stabilisation with geogrids for transport applications - selected issues
}

\author{
Jacek Kawalec ${ }^{1,2, *}$ \\ ${ }^{1}$ Silesian University of Technology, Department of Geotechnics and Roads, Gliwice, Poland \\ ${ }^{2}$ Tensar International s.r.o., Cesky Tesin, Czech Republic
}

\begin{abstract}
Stabilisation is defined as improvement of the mechanical properties of an unbound granular material by including one or more geosynthetic layers such that the deformation under applied loads is reduced by minimizing soil particle movement. Paper discuss geogrids as type of geosynthetics which when used in stabilisation function for transport applications could provide real improvement in performance of aggregate layer. Such function has been called for a quite long time as the reinforcement of subbase, base or ballast, depending on the application
\end{abstract}

\section{Introduction}

Stabilisation / stiffening is a mechanism leading to reduction of particle movement achieved through confinement. It is very important in geotechnical engineering as tool to improve compaction (Kumor and Kumor, 2016; Zabielska-Adamska and Sulewska, 2013) or reduce vibrations (Rybak and Pieczynska-Kozlowska, 2014). This function of geosynthetic is commonly used in road and railway engineering (Cook et al., 2016; Grygierek and Kawalec, 2017; Zornberg, 2017). It results in reduction of deformation within non-cohesive materials under load. Stabilisation as function of geosynthetic was recently newly formally defined by ISO TC221 as "Improvement of the mechanical properties of an unbound granular material by including one or more geosynthetic layers such that the deformation under applied load is reduced by minimizing soil particle movement". The function has been called for quite a long time as the reinforcement of subbase, base or ballast according to the application (Giroud and Han; 2016; Rakowski, 2017). Only recent observations both from laboratories and field prove that it is not the strength which is the factor controlling this function but that certain stiffening of granular material by interlocking is the most important one. Because this function is different than soil reinforcement hereafter geosynthetic features and performance related parameters are different than for reinforcement. Mechanical properties of mechanically stabilised layers using geogrids are still not defined enough. There is a number of researchers and Engineers who are actively involved in various research and applications with use of geosynthetics for stabilization (Grygierek, 2017; Robinson et al. 2018; Sun et al. 2015; Tutumluer et al., 2012; Oliver et al. 2016)

The mechanism of aggregate stabilisation under dynamic load from train is achieved thanks to grain interlocking within non-deformable aperture of the stiff geogrid (see Figure 1).

\footnotetext{
*Corresponding author: jacek.kawalec@vp.pl
} 
Stiff geogrid ribs resist particle movement, also under cyclic loading, preventing layer deformation. One of the effects of stabilisation of an aggregate with a geogrid is an increase in stiffness or modulus of the layer. The modulus of unbound aggregate is a function of the stress state $(\Theta)$. Several relationships allowing for the calculation of aggregate modulus exist in literature, one of them is presented in AASHTO Guide for Design of Pavement Structures [1]:

where:

$$
E=k_{1} \Theta^{k_{2}}
$$

$\Theta$ - the sum of principal stresses $\left(\sigma_{1}+\sigma_{2}+\sigma_{3}\right)$

$\mathrm{k}_{1}, \mathrm{k}_{2}-$ constants that depend upon aggregate type.

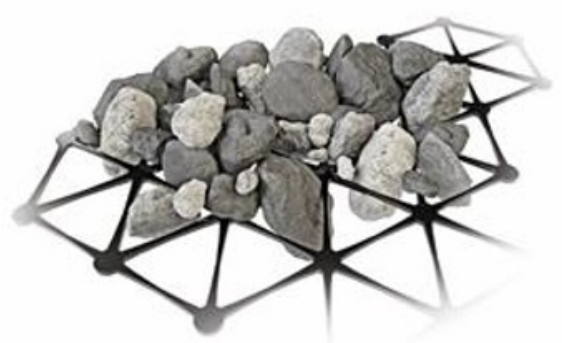

Fig. 1. Interlocking mechanism shows grains being locked in aperture of monolithic geogrid.

When a trafficking load is applied to a layer, the stiff ribs of the geogrid react, preventing aggregate particles from moving laterally. This increases the horizontal principal stresses, $\sigma_{2}$ and $\sigma_{3}$, and $\Theta$ increases as a result. When $\Theta$ increases, the modulus of a layer increases and so does its bearing capacity.

The grain penetration through apertures may occur also with flexible geogrids (eg. woven) but then there is no horizontal support against micro displacement resulting in weaker performance. This differentiation in performance is known for nearly quarter of century eg. from early US Corps of Engineers (Webster 1993). The differences in initial stiffness for different geosynthetic are shown on Figure 2 where it's clearly visible that Modulus E for low displacement are dependent on product characteristics.

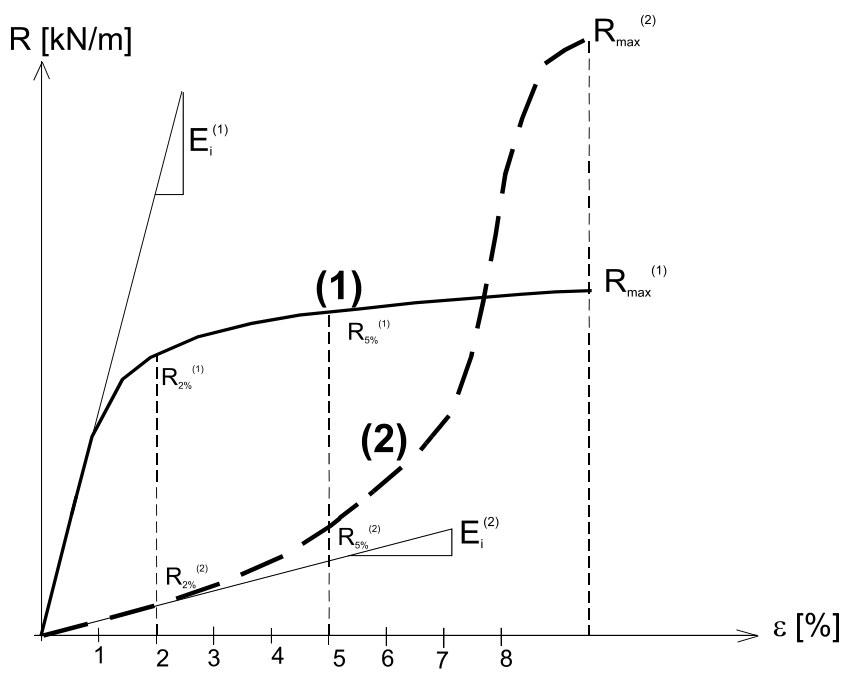

Fig. 2. Characteristic for stiff geogrid (1) vs. flexible geogrid (2) showing difference in modulus at low deformation. 
As effect of interlocking, stiff geogrid provides confinement to aggregate not only in plane but also within some distance. Three zones could be described here (Figure 3):

- Full confinement zone (h3) at geogrid level up to distance of several grain size. Within this zone grain displacement is practically not possible due to interlocking.

- Transition zone (h2) where confinement is reduced from full (at bottom of the zone) to zero (at top of the zone). Grain ability to move is increasing within distance from geogrid. This reduction is non-linear and is dependent on individual features of both geogrid and aggregate.

No confinement zone (h1) where only internal friction is acting against displacement of grains. To stabilize grains within this zone next layer of stiff geogrid is required.

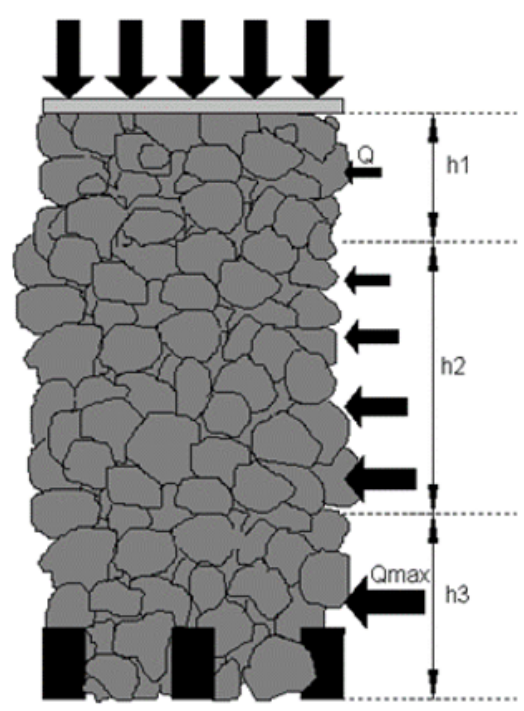

Fig. 3. Three zones over geogrid representing different confinement effect to aggregate.

Such considerations are bringing us into discussion on mechanism of stabilisation. In contrast to reinforcement, stabilisation is considered at very low displacement level, far below elongations measured at product rapture and described as tensile strength (Qian et al., 2018). As consequence stabilisation mechanism is key function for most of transport infrastructure applications like railways, paved and unpaved roads, container terminal and other trafficked areas. It could be useful in any kind of future development of transport infrastructure in cities (Il ichev et al., 2012; Kositsyn et al., 2018), giving also additional environmental benefits (Kawalec et al., 2018)

But it's important to remember that to achieve proper stabilization effect we also need a right drainage, if this is a not possible via natural formations then proper geosynthetics for drainage also could be used (Miszkowska et al., 2017).

\section{Stabilisation of railway ballast}

Ballast stabilization is considered as application for extension of time intervals between maintenance periods (Petraiev et al., 2017, Horton et al., 2017). Use of geogrid reduces speed of deformation of the layer under applied dynamic loads and postpone tamping with time. Hornicek et al., 2017 provided results from extensive observations of track with sections with and without geosynthetics carried on one of main railway tracks in Czech Republic. 


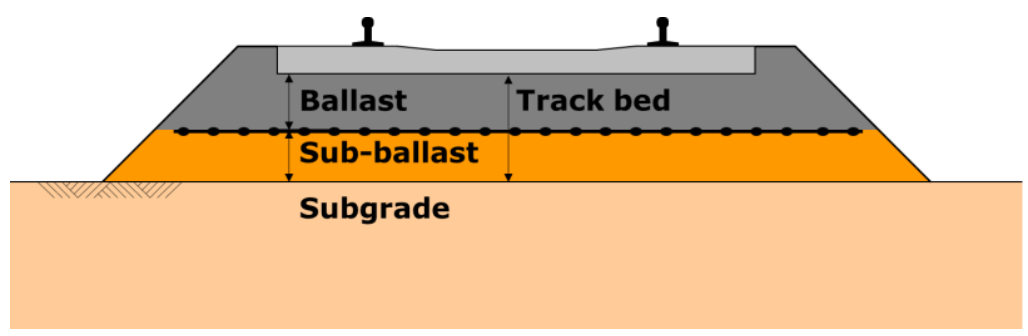

Fig. 4. Location of geogrid for ballast stabilization.

Section with geocomposite (stiff hexagonal geogrid with laminated geotextile) showed significant improvement in modulus measured over observation period (Fig. 5) vs sections without geosynthetic installed.

Very interesting research was carried out by Penn State University. As reported by Liu et al., 2016 an artificial laboratory made stones named SmartRock equipped with sensors were used to understand differences in movements and rotations of single grain within ballast layer under applied dynamic cyclic loads. SmartRock is installed above geogrid in the test and record real-time particle movement including translation and rotation. The results of this research showed significant reduction in particle angular acceleration in all three directions $\mathrm{x}, \mathrm{y}$ and $\mathrm{z}$. It could be concluded that thanks to such reduction of movement aggregate layer deterioration in time will also be slowed what leads to extension in serviceability of ballast over time.

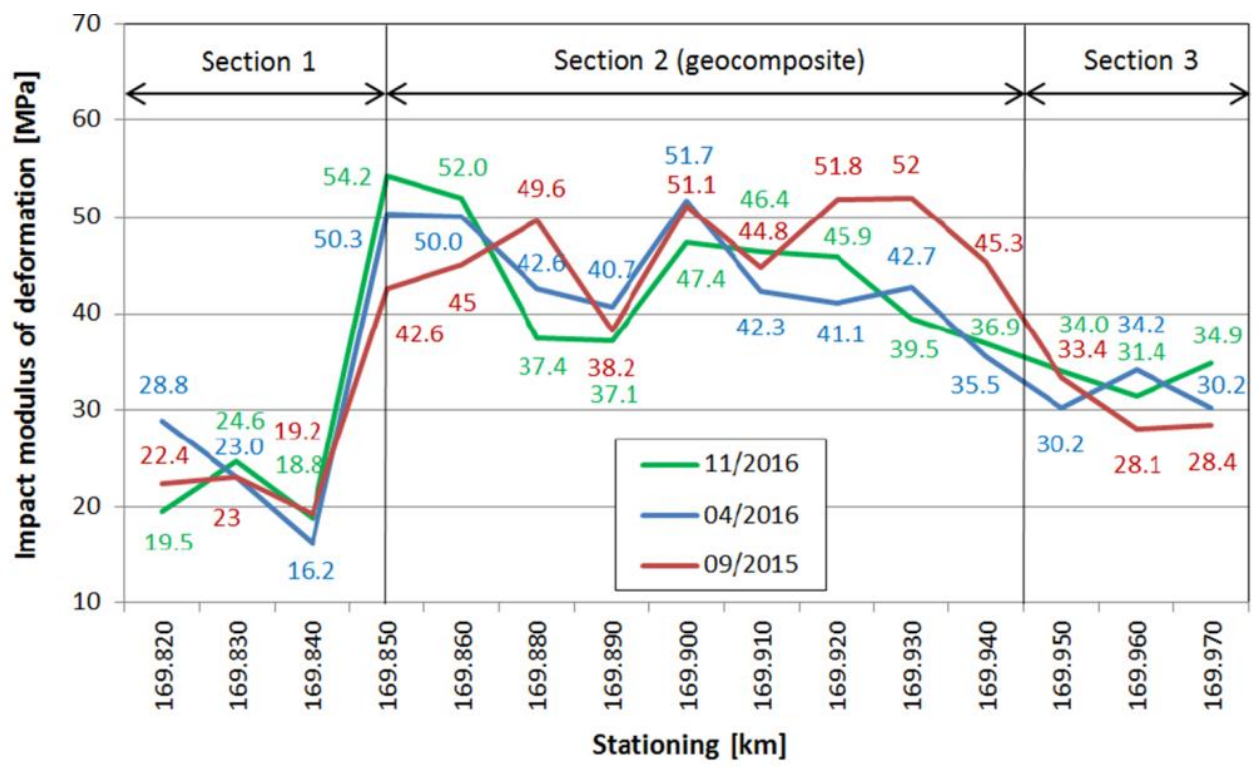

Fig. 5. Measurement of modulus along observed track on different sections (Hornicek et al., 2017).

Such research results are applicable to any kind of aggregate layer stabilized by geogrid, independently if application is in road railways or any other trafficked areas. In particular it could improve suitability of the aggregate (Krawczyk et al., 2018) 

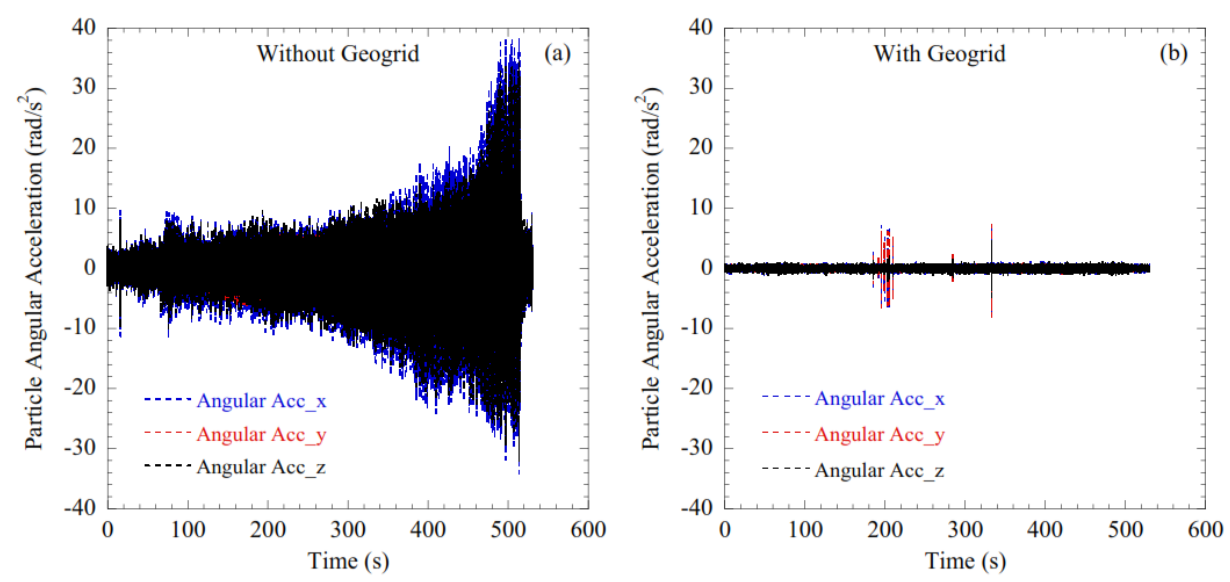

Fig. 6. Reduction in particle angular acceleration over time, Liu et al. 2016.

\section{Stabilisation of railway sub-ballast}

Sub-ballast stabilization is one of typical application of geogrids in case of weak soils under rail track (Horton et al., 2017). Depending on soil condition it could be single, double or multi- layer structure (Fig. 7, 8). This application is commonly used across globe by railway administration to improve modulus. Also some research results are known on performance of geogrid in sub-ballast. According to Prof. Asphiz and Prof. Belyaev sleeper settlement speed under applied load is reduced by over 10 times if geogrid is used to stabilize sub-ballast (Fig. 10).

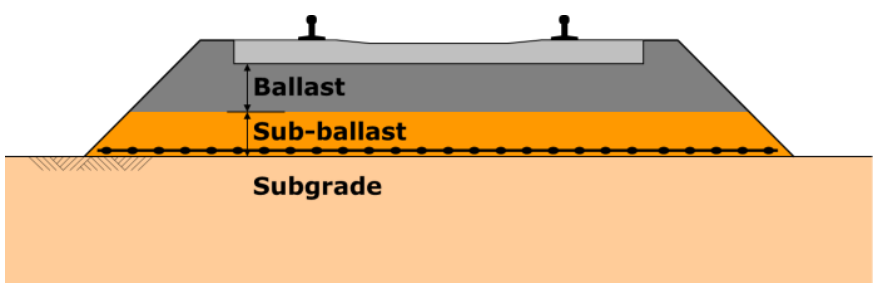

Fig. 7. Location of geogrid for sub-ballast stabilization.

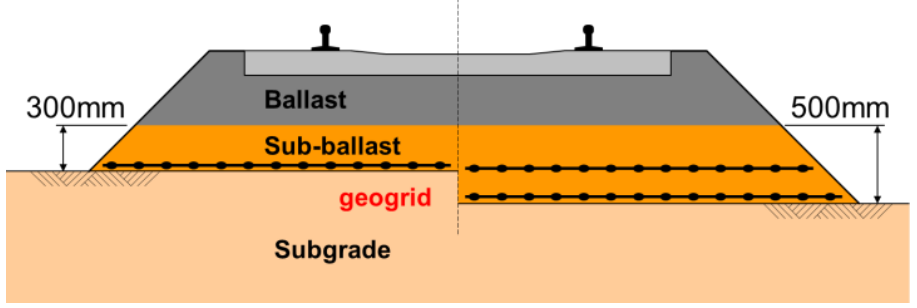

Fig. 8. Location of geogrid for sub-ballast stabilization in single and double layer structure.

On Figure 9 combination of ballast and sub-ballast stabilization is presented. This is not often used solution, however some railway administration decide to use it within same maintenance works. Example of installation is presented on Fig. 11.

One of possible application which is not well verified is use of stabilizing geogrids in regions with soil freezing (Ulitskii et al., 2015). 


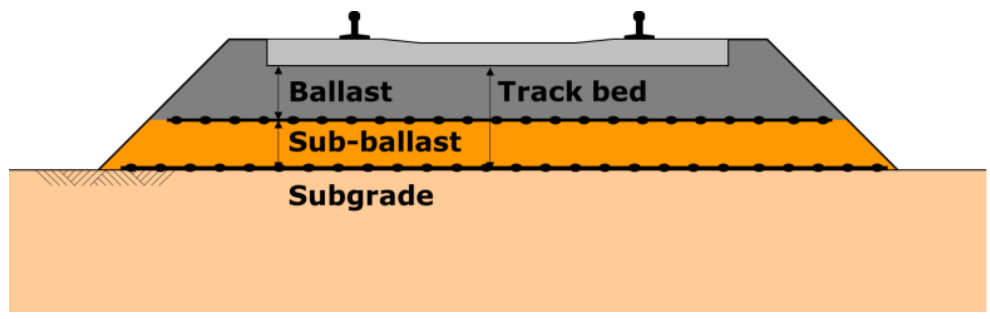

Fig. 9. Location of geogrid for ballast and sub-ballast stabilization.

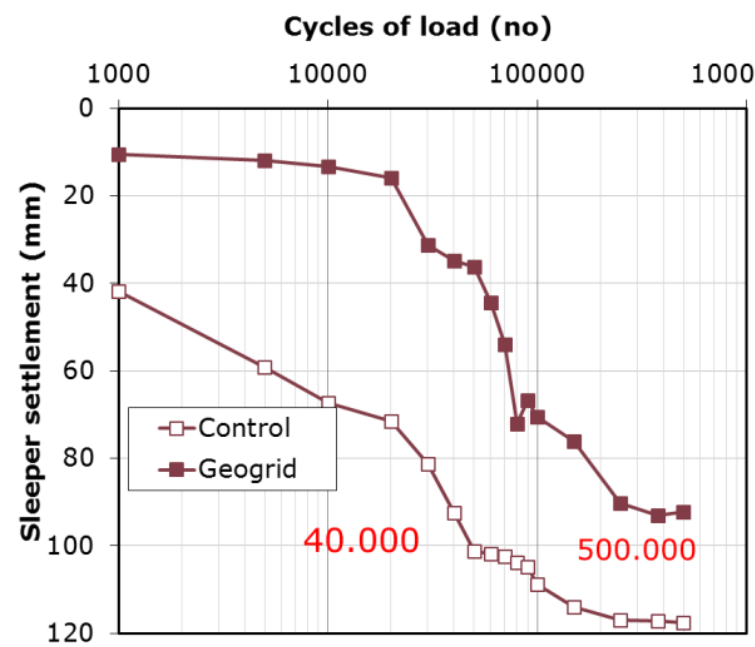

Fig. 10. Track bed stabilization according to research by Prof. Asphiz and Prof. Belyaev.

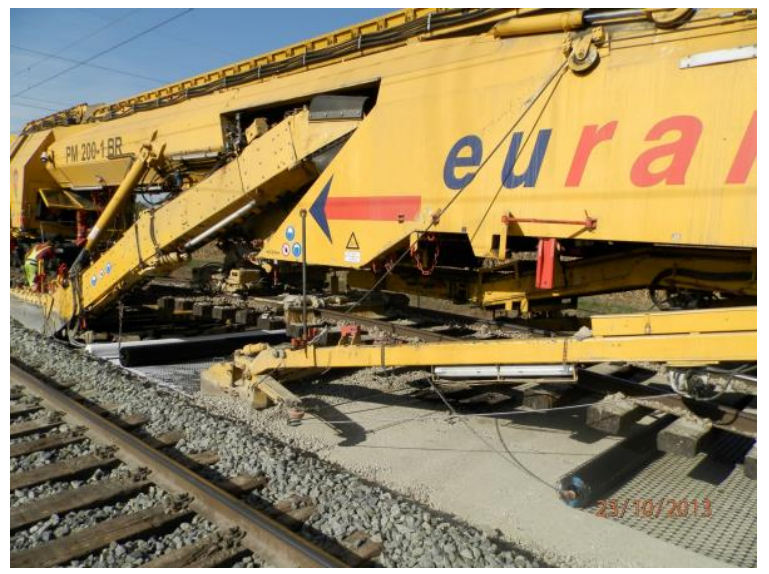

Fig. 11. Installation of sub-ballast and ballast stabilization in one maintenance operation.

\section{Repair of muddy ballast beds}

Quite often observed problem of mud spots on railways could also effectively solved by stabilizing layer of geogrid with aggregate. This problem mentioned by Hornicek et al, 2017 is solved in Czech Republic by conventional track renewal what means replacement of ballast and often sub-ballast. The problem is showed on Fig12 whilst application of geogrid to solve the problem is present of Fig. 13. 


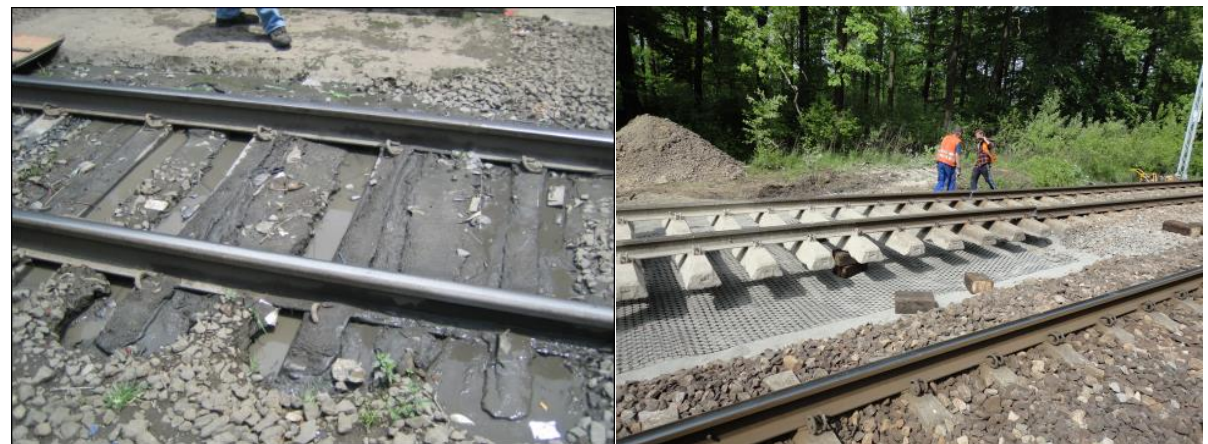

Fig. 12. Problem of muddy ballast.

Fig. 13. Solution with geogrid.

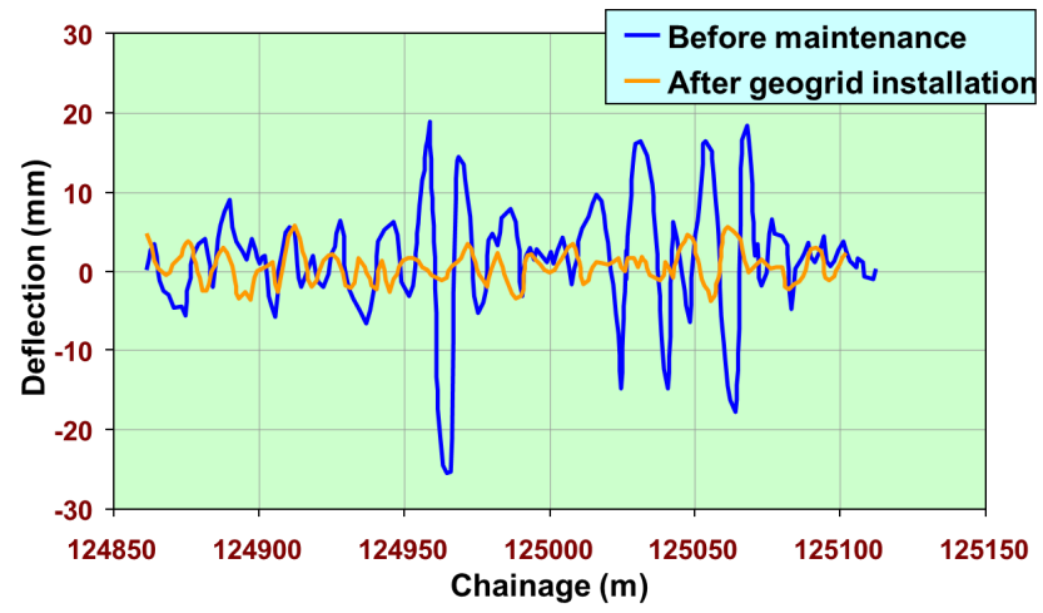

Fig. 14. Reduction in deflection observed on one test section in Hungary.

As shown on Fig. 14 installation of geogrid for stabilization reduced deflection of monitored section. In locations with highest deflection prior to installation was reduced over 20 times. But the important achievement is that deflection becomes regular within chainage.

\section{Conclusions}

Geogrids in stabilization function are showing improvement of serviceability of aggregate layers in trafficked application. But the support from geogrid should not be under consideration without aggregate. Type of aggregate, right granulation for type of grid, sharp edges of stones, and proper compaction are also essentially important to achieve good confinement.

\section{References}

1. J. Cook, M. Dobie, D. Blackman, The development of APT methodology in the application and derivation of geosynthetic benefits in roadway design. In The Roles of Accelerated Pavement Testing in Pavement Sustainability (Springer, 2016)

2. J. Giroud, J. Han, Geosynthetics 34-1, 22-36 (2016) 
3. M. Grygierek, J. Kawalec, Procedia Engineering 189, 484-491 (2017)

4. M. Grygierek, IOP Conference Series: Materials Science and Engineering 245-4, 042051 (2017)

5. L. Hornicek, P. Brestovsky, P. Jasansky, IOP Conference Series: Materials Science and Engineering 236-1, 012039 (2017)

6. M. Horton, D.P. Connolly, Z. Yu, Rail, Procedia engineering 189, 924-931 (2017)

7. V.A. Il'ichev, R.A. Mangushev, N.S. Nikiforova, Soil Mechanics and Foundation Engineering 49(2), 63-67 (2012)

8. J. Kawalec, M. Golos, P. Mazurowski, IOP Conference Series: Materials Science and Engineering 356-1, 012018 (2018)

9. B. Krawczyk, A. Szydlo, P. Mackiewicz, D. Dobrucki, Roads and Bridges-Drogi i Mosty 17(1), 39-53 (2018)

10. S.B. Kositsyn, V.S. Fedorov, V.Y. Akulich, Scientific Herald of the Voronezh State University of Architecture \& Civil Engineering 37(1) (2018)

11. L.A. Kumor, M.K. Kumor, Transportation Research Procedia 14, 787-796 (2016)

12. S. Liu, H. Huang, T. Qiu, J. Kwon, Transportation Geotechnics 9, 110-122 (2016)

13. A. Miszkowska, S. Lenart, E. Koda, Water 9(9), 660 (2017)

14. T. Oliver, M. Wayne, J.mKwon, Procedia Engineering 143, 896-910 (2016)

15. A. Petriaev, A. Konon, V. Solovyov, Procedia engineering 189, 654-659 (2017)

16. Z. Rakowski, Procedia Engineering 189, 166-173 (2017)

17. W.J. Robinson, J.S. Tingle, G.J. Norwood, M.H. Wayne, J. Kwon, Proceedings of the Institution of Civil Engineers - Ground Improvement 1-32 (2018)

18. J. Rybak, J.M. Pieczynska-Kozlowska, 14th International Multidisciplinary Scientific GeoConference SGEM 2014: GeoConference on science and technologies in geology, exploration and mining 2, 1043-1050 (2014)

19. X. Sun, J. Xan, J. Kwon, R.L. Parsons, M.H. Wayne, Geotextiles and Geomembranes 43(5), 440-449 (2015)

20. E. Tutumluer, H. Huang, X. Bian, International Journal of Geomechanics 12-4, 391398 (2012)

21. Y. Qian, E. Tutumluer, D. Mishra, H. Kazmee, Proceedings of the Institution of Civil Engineers-Ground Improvement 1-22 (2018)

22. V. Ulitskii, I. Sakharov, V. Paramonov, S. Kudryavtsev, Soil Mechanics \& Foundation Engineering 52(5) (2015)

23. S.L. Webster, Geogrid reinforcement base courses for flexible pavements for light aircrafts, Technical Report GL-93-6 (US Army Engineers Waterways Experiment Station, Vicksburg, 1993)

24. K. Zabielska-Adamska, M.J. Sulewska, Dynamic CBR as a method of embankment compaction assessment (2013) 